\title{
LA GENEALOGÍA DE LOS REYES DE ESPAÑA DE ALONSO DE CARTAGENA: LINAJE E IMAGEN REGIA EN LA CASTILLA DEL CUATROCIENTOS*
}

\author{
David Nogales Rincón \\ Universidad Complutense de Madrid \\ dnogales@ucm.es
}

La Genealogía de los reyes de España-también conocida como Liber Genealogie regum Hispaniae o tardíamente como Anacephaleosis- de Alonso de Cartagena (referida, a partir de ahora, como Genealogía), obra historiográfica latina finalizada en 1456 que aborda sucintamente la Historia primitiva de la península ibérica, seguida de las semblanzas de los reyes de España desde Atanarico hasta Enrique IV de Castilla, ha sido ampliamente estudiada desde el punto de vista historiográfico, con algunas aproximaciones particulares a su proyecto iconográfico ${ }^{1}$.

* Plan Nacional de Investigación Científica, Desarrollo e Innovación Tecnológica (subprograma Juan de la Cierva) de la Secretaría de Estado de Investigación, Desarrollo e Innovación del Ministerio de Economía y Competitividad del Gobierno de España. Proyecto de I+D del Programa Estatal de Fomento de la Investigación Científica y Técnica de Excelencia, Subprograma de Generación del Conocimiento (2015-2017) HAR2013-42211-P de la Secretaría de Estado de Investigación, Desarrollo e Innovación, Prácticas de Comunicación y negociación en las relaciones de consenso y pacto de la cultura política castellana, ca. 1230-1504.

${ }^{1}$ Es posible destacar, en este sentido: Elías Tormo, Las viejas series icónicas de los reyes de España, Madrid, Junta de Iconografía Nacional, 1917, pp. 219-256, 287-288; Robert B. Tate, Ensayos sobre la historiografia peninsular del siglo xV, Madrid, Gredos, 1970, pp. 55-73; Luis Fernández Gallardo, «La obra historiográfica de dos conversos ilustres, don Pablo de Santa María y don Alonso de Cartagena», en Espacio, Tiempo y Forma. Serie III. Historia Medieval, 6 (1993), pp. 249-286; Anna Muntada, «Un ejemplar de la Genealogía de los Reyes de España de Alonso de Cartagena en manos de la emperatriz Isabel de Portugal», en Bulletí del Museu Nacional d'Art de Catalunya, 2 (1994), pp. 169-184; Bonifacio Palacios Martín, «Estudios histórico y doctrinal de las Genealogías», en El Libro de la Genealogía de los Reyes de España de Alfonso de Cartagena, Valencia, Biblioteca Nacional de España; Scriptorium, 1995, II, pp. 87-126; José L. Rodríguez Montederramo, «Las glosas latinas a la Anacephaleosis y las adiciones de Juan de Villafuerte», en Reales Sitios, 129 (1996), pp. 16-25; Elisa Ruiz García, «El sueño de la edición múltiple: unos testimonios tempranos», en Pliegos de Bibliofilia, 8 (1999), pp. 5-24; Elisa Ruiz García, «Avatares codicológicos de la Genealogía de los Reyes de España», en Historia. Instituciones. Documen- 
El objetivo del presente trabajo es ofrecer una aproximación a los distintos testimonios manuscritos, las posibles relaciones entre los mismos y su contexto de recepción, a partir del estudio de su programa iconográfico y de su relación con el texto.

\section{La Genealogía de los reyes de España y la historiografía cuatrocentis- ta: contexto genérico y audiencia}

El contexto genérico en el que se enmarca la labor historiográfica de Alonso de Cartagena se encuentra delimitado, según nos indica el propio obispo de Burgos en el prólogo a la Genealogía (f. $5 \mathrm{v})^{2}$, por dos subgéneros historiográficos: por un lado, el árbol (arbor), fórmula narrativa breve que se acompañaría de la representación de las relaciones genealógicas bajo forma diagramática ${ }^{3}$. Por otro lado, la crónica (historia), extenso relato historiográfico cuyo modelo se podría encontrar, como apunta el obispo de Burgos, en De

tos, 27 (2000), pp. 295-332; Robert Folger, «The Anacephaleosis (1456) of Alfonso de Cartagena: How to Digest Chronicles», en Die Praktiken der Gelehrsamkeit in der Frühen Neuzeit, Tubinga, Max Niemeyer, 2001, pp. 31-49; Luis Fernández Gallardo, Alonso de Cartagena. Una biografia política en la Castilla del siglo XV, Valladolid, Junta de Castilla y León, 2002, pp. 277-319; Laurette Godinas, «Alonso de Cartagena y la así llamada Anacephaleosis o las vicisitudes de un texto histórico del siglo XV», en Visiones y crónicas medievales, México D.F., Universidad Nacional Autónoma de México; Universidad Autónoma Metropolitana; El Colegio de México, 2002, pp. 131-145, pp. 137-139; Isabel Mateo Gómez, Sobre el autor de los dibujos de la Genealogía de los Reyes de don Alonso de Cartagena, Burgos, Academia Burgense de Historia y Bellas Artes; Institución Fernán González, 2005; David Chao Castro, Iconografía regia en la Castilla de los Trastámara, tesis doctoral inédita, Santiago de Compostela, Universidad de Santiago de Compostela, 2005, pp. 243-251, 316-329; Luis Fernández Gallardo, «Idea de la Historia y proyecto iconográfico en la Anacephaleosis de Alonso de Cartagena», en Anuario de Estudios Medievales, 40:1 (2010), pp. 317-353; David Nogales Rincón, «Cultura visual y genealogía en la corte regia de Castilla durante la segunda mitad del siglo XV», en e-Spania, 11 (2011), pp. 37-51. [En línea]. Enlace: $<\mathrm{http} / / \mathrm{e}-$ spania.revues.org/20362>. [Consulta: 01/03/2016]. DOI: 10.4000/e-spania.20362.

${ }^{2} \mathrm{~A}$ lo largo del texto, salvo que se indique lo contrario, citamos por la traducción de Juan de Villafuerte correspondiente al testimonio $\mathrm{P}$.

${ }^{3}$ Sobre la representación gráfica del parentesco existe una amplia bibliografía, entre la que es posible destacar: Javier Martínez de Aguirre, «En torno a la iconografía de la familia en el Occidente medieval», en La familia en la Edad Media: XI Semana de Estudios Medievales, Logroño, Gobierno de la Rioja; Instituto de Estudios Riojanos, 2001, pp. 403-454; Rosa M. ${ }^{a}$ Rodríguez Porto, «Otros reyes de la su casa onde él venían: metáforas, diagramas y figuras en la historiografía castellana (1282-1332)», en Revista de poética medieval, 27 (2013), pp. 197-232; Marigold Anne Norbye, «Arbor genealogiae: Manifestations of the Tree in French Royal Genealogies», en The Tree. Symbol, Allegory, and Mnemonic Device in Medieval Art and Thought, Turnhout, Brepols, 2014, pp. 69-94; Íd., «Genealogies in Medieval France», en Broken Lines. Genealogical Literature in Late-Medieval Britain and France, Brepols, Turnhout, 2008, pp. 79-102; Olivier de Laborderie, Histoire, mémoire et pouvoir: les généalogies en rouleau des rois d'Angleterre (1250-1422), París, Classiques Garnier, 2013; Christiane Klapisch-Zuber, L'ombre des ancêtres. Essai sur l'imaginaire médiéval de la parenté, París, Fayard, 2000, con referencia específica a la figura del árbol en Christiane Klapisch-Zuber, «De la nature végétale de l'arbre généalogique», en Le monde végétal. Médecine, botanique, symbolique, Florencia, SISMEL Edizioni del Galluzzo, 2009, pp. 447-468. 
rebus Hispaniae de Rodrigo Jiménez de Rada (ff. 25r, 99v) o en la Estoria de España de Alfonso X (f. 173r). En este punto, Cartagena buscaría en su planteamiento inicial situar la Genealogía, en lo que a su prolijidad y extensión se refiere, en un punto intermedio entre ambos subgéneros (f. $5 \mathrm{v}$ ), asociando su obra a las ideas de «breve compendio» (f. 5v), «brevezilla obra» (f. 6r) o «suma» (f. $9 \mathrm{v}$ ), aspecto que permitiría enmarcarla dentro del subgénero que se ha dado en denominar como sumarios de crónicas ${ }^{4}$.

La Genealogía no supone, en comparación con otros sumarios, una innovación sustancial desde el punto de vista de su estructura, que sigue la habitual ordenación cronológica por reinados. Muestra, no obstante, un interés particular por la genealogía, manifestado en su atención hacia diversas cuestiones de tipo familiar, sobre las que se sustentaría, en buena medida, la idea de continuidad histórica de la realeza castellana desde el período visigodo hasta el reinado de Enrique IV (1454-1474). Todo ello con el objetivo último de mostrar, atendiendo a la antigüedad de su realeza, la preeminencia de Castilla sobre las restantes monarquías peninsulares y su importancia en el contexto de la Cristiandad ${ }^{5}$.

Dirigida la versión preliminar de la Genealogía al rey Juan II de Castilla (1406-1454), a la muerte del monarca, en julio de 1454, según relata Cartagena, el proyecto quedó aparcado (ff. 5v-6r). Algunos meses después, hubo de ser retomado, ahora reformulado bajo el propósito de una mayor brevedad y con un nuevo dedicatario, el cabildo de la catedral de Burgos (ff. 6r-v, 8rv). Este cambio de destinatario sería justificado por Cartagena atendiendo a la preeminencia de Burgos y a la posición de su Iglesia como custodia de la memoria del reino, en condición de la Iglesia y el concejo de Burgos como «cabeças, la Iglesia de las Iglesias e la cibdat de las cibdades de Castilla» (f. $8 \mathrm{v})$. Reorientación que cabría poner probablemente en relación con el conflicto de preeminencias que habría tenido lugar entre las sedes burgalesa y toledana, entre los años 1448 y $1453^{6}$.

La Genealogía, en su planteamiento primitivo, se presentaba como una síntesis de la Historia de Castilla, a manera de aproximación preliminar a las historias más prolijas y como instrumento para el desenvolvimiento cortesano, en torno a la plática de naturaleza histórica (f. $5 \mathrm{v}$ ). El cambio de destinatario no hubo de suponer una reorientación sustancial de la obra, cuya

\footnotetext{
${ }^{4}$ Jean-Pierre Jardin, «El modelo alfonsí ante la revolución trastámara. Los sumarios de crónicas generales del siglo XV», en La historia alfonsí: el modelo y sus destinos (siglos XIII-XV), Madrid, Casa de Velázquez, 2000, pp. 141-156, habiendo sido incluida la Genealogía dentro de este subgénero en ibídem, p. 143.

${ }^{5}$ Bonifacio Palacios Martín, art. cit., p. 107.

${ }^{6}$ Sobre este aspecto, véase Jorge Díaz Ibáñez, «Alonso de Cartagena y la defensa de la exención del obispado burgalés frente al primado toledano», en En la España Medieval, 34 (2011), pp. 325-342.
} 
estructura y contenidos serían acordes, en buena medida, si atendemos a su versión final, con el planteamiento historiográfico primitivo. En este sentido, esta dimensión de vademécum o de manual histórico de la Genealogía explicaría, al menos, parcialmente, el interés de Cartagena por atender a las informaciones de otros soberanos occidentales «non ssolamente [para] procurar deleite, mas aún para conoscer algunas cosas que a las vezes buscamos mucho aprovecha» (f. 7r), sin olvidar su papel como transmisora de exempla morales (ff. 107r-v, 197v-198r).

\section{La recepción de la Genealogía de los Reyes de España: algunas notas sobre los testimonios y su transmisión textual}

La condición de la Genealogía como obra dirigida a la vulgarización de la historia de Castilla explica probablemente su amplia difusión, con un número significativo de manuscritos conocidos -siete testimonios latinos (Biblioteca Nacional de España (BNE), Res. 35, ff. 1r-51v [N' ${ }^{1}$, ms. 7432, ff. 1r-88r $\left[\mathrm{N}^{2}\right]$, ms. $13260\left[\mathrm{~N}^{3}\right]$ y Vitr. 19/2 [N $\left.\mathrm{N}^{4}\right]$; Houghton Library (HL), Typ. $162[\mathrm{H}]$; Biblioteca Comunale de Fermo, 77 [F]; Archivo Histórico Nacional (AHN), Códices y Cartularios (CC), Lib. 983 [A]) y nueve castellanos (BNE, ms. 9436, ff. 1r-196v [N $\left.\mathrm{N}^{5}\right]$, ms. $815\left[\mathrm{~N}^{6}\right]$, ms. $8210\left[\mathrm{~N}^{7}\right]$, ms. $7073\left[\mathrm{~N}^{8}\right]$ y ms. $22580\left[\mathrm{~N}^{9}\right]$; Biblioteca del monasterio de San Lorenzo de El Escorial (B.

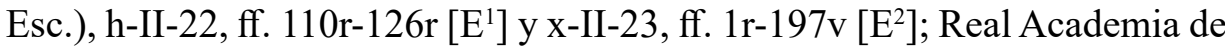
la Historia (RAH), 9/5573 [R ${ }^{1}$ ], Colección Salazar y Castro, N-24, ff. 128r$149 \mathrm{v}\left[\mathrm{R}^{2}\right]$; Real Biblioteca, II/3009 [P])- y tres ediciones impresas latinas (Granada, 1545; Fráncfort, 1579; Fráncfort, 1603).

La recepción de la obra en los años inmediatos a su composición, período en el que centraremos nuestro análisis, parece tener lugar principalmente en torno a dos contextos: el entorno del difunto obispo de Burgos y la corte real de Castilla. Con respecto a los testimonios latinos, es posible señalar probablemente a $\mathrm{N}^{2}$ como el testimonio más antiguo conocido. Se trataría de un

\footnotetext{
${ }^{7}$ Para una descripción de los distintos testimonios manuscritos y ediciones, véase: Bonifacio Palacios Martín, «Descripción del manuscrito», en El libro de la Genealogía de los Reyes de España de Alfonso de Cartagena, Valencia, Biblioteca Nacional de España; Scriptorium, 1995, t. II, pp. 61-86, pp. 65-71; Yolanda Espinosa Fernández, La Anacephaleosis de Alonso de Cartagena: edición, traducción, estudio, Madrid, Universidad Complutense de Madrid, 1989, vol. I, pp. 136-212; Elisa Ruiz García, «El sueño...», p. 10; María Morrás, «Repertorio de obras, mss. y documentos de Alfonso de Cartagena ( $c a$. 1384-1456)», en Boletín Bibliográfico de la Asociación Hispánica de Literatura Medieval, 5 (1991), pp. 213-248, pp. 232-233. Específicamente para el testimonio $\mathrm{E}^{1}$ : Juan C. Conde, La creación de un discurso historiográfico en el cuatrocientos castellano: «Las siete edades del mundo» de Pablo de Santa María: estudio y edición crítica, Salamanca, Ediciones Universidad de Salamanca, 1999, pp. 140-145.
} 
manuscrito del entorno de Cartagena ${ }^{8}$, sobre el que, a manera de borrador, se hubieron de llevar a cabo diversas correcciones, realizadas en vida del obispo de Burgos o poco después de su muerte; hecho que quizá explique la ausencia de título y de los epígrafes correspondientes a los capítulos.

Ligeramente posteriores -anteriores, en cualquier caso, al menos, $\mathrm{N}^{1}$, al año $1465^{9}$ - parecen ser los testimonios $\mathrm{N}^{1}$ y A, que guardan una estrecha relación con $\mathrm{N}^{2}{ }^{10}$. Ambos testimonios incorporan numerosas glosas en latín -que llamativamente aparecen insertas en el testimonio $\mathrm{H}$ en el cuerpo del texto, bajo la etiqueta de additio- y parecen escritos con una letra y siguiendo un sistema de abreviaturas similares. En este sentido, Elisa Ruiz García considera que $\mathrm{N}^{1} \mathrm{y}$ A, junto con $\mathrm{N}^{2}$, fueron copiados «por manos de formación gráfica universitaria y de ascendencia extrapeninsular», en los que sería posible adivinar «una influencia nórdica -francesa o centroeuropea» ${ }^{11}$. Este aspecto, junto al hecho de que el códice misceláneo que incluye $\mathrm{N}^{1}$ contenga el texto de la Coronación de la corona argéntea et áurea del emperador Sigismundo $^{12}$, dirigido por el abad de Cervatos, Alfonso García de Fuentes, a Alonso de Cartagena, reforzaría su probable vinculación con el entorno del obispo de Burgos ${ }^{13}$, reflejando, a su vez, los distintos textos reunidos en este códice misceláneo BNE, Res. 35, en palabras de José L. Rodríguez Montederramo, «el marco de intereses intelectuales en el que se gestaron la versión y glosas de [Juan de] Villafuerte ${ }^{14}$, sobre las que hablaremos a continuación. Con posterioridad, este testimonio $\mathrm{N}^{1}$ pudo quizá llegar al entorno de los

\footnotetext{
${ }^{8}$ Es significativo el hecho de que $\mathrm{N}^{2}$ contenga De actibus Alfonsi de Cartagena (ff. 89r-92v), así como una referencia a la condición como copista de Juan Sánchez de Nebreda (f. 71v), vinculado al entorno de Cartagena. Cfr. José L. Rodríguez Montederramo, art. cit., p. 17; Elisa Ruiz García, «El sueño...», p. 8. Así, este Juan Sánchez de Nebreda o Juan de Nebreda aparece como copista («Istum librum perfecit Iohannes de Nebreda», BNE, ms. 12796, f. 119v) de un ejemplar del Doctrinal de caballeros de Alonso de Cartagena, aunque no parece, siguiendo a Jeremy Lawrance, que pueda ser considerado, como en ocasiones se ha supuesto, como el autor de De actibus, salido quizá de la pluma de Diego Rodríguez de Almela. Jeremy Lawrance, «De actibus Alfonsi de Cartagena: Biography and the Craft of Dying in Fifteenth-Century Castile», en Text \& Manuscript in Medieval Spain. Papers from the King's College Colloquium, Londres, King's College. Department of Spanish \& Spanish-American Studies, 2000, pp. 121-184, pp. 121-126.

${ }^{9}$ En esta fecha se añadiría una glosa marginal en BNE, Res. 35, f. $12 \mathrm{v}$.

${ }^{10}$ En este sentido, ambos testimonios se encargan de refundir e incorporar diversas correcciones presentes en $\mathrm{N}^{2}$. Es difícil establecer con absoluta precisión las relaciones entre $\mathrm{A} \mathrm{y}^{1}$, si bien es probable que $\mathrm{A}$ sea copia de $\mathrm{N}^{1}$, atendiendo, en primer lugar, a que $\mathrm{A}$ se aleja, al disponer el texto en dos columnas, tanto de $\mathrm{N}^{1}$ como de $\mathrm{N}^{2}$, ambos a una columna; en segundo lugar, a que una corrección -que no se encuentra en otros testimonios, como $\mathrm{N}^{4} \mathrm{o}$ la edición impresa en Fráncfort, 1603- presente en $\mathrm{N}^{1}$ (f. $4 \mathrm{v}$ ) hubo de pasar a A (f. 14r).

${ }^{11}$ Elisa Ruiz García, «Avatares...», p. 302.

${ }^{12}$ BNE, Res. 35, ff. 76r-78v.

${ }^{13}$ José L. Rodríguez Montederramo, art. cit., p. 23.

${ }^{14}$ Ibídem, p. 23.
} 
arzobispos de Toledo, pues en nota marginal se consignaron distintas noticias sobre los mismos, relativas a los siglos $\mathrm{XV} \mathrm{y} \mathrm{XVI}^{15}$.

A estas versiones latinas se hubo de sumar el romanceamiento, finalizado el 21 de noviembre de 1463, realizado por Juan de Villafuerte ${ }^{16}$, quien añadió una extensa glosa al texto, basada, como ha apuntado Rodríguez Montederramo, en las glosas latinas ${ }^{17}$. Es complicado conocer las circunstancias precisas de la traducción. No deja de ser llamativo, en cualquier caso, que, aunque el razonamiento del trasladador no se encuentre dirigido expresamente a ningún dedicatario concreto, algunos testimonios incluyan una referencia epilogal con una suplicación dirigida «a la real discreción e a los oyentes» ${ }^{18}$, que seguiría de cerca el proemio a la autotraducción del Breviloquio de amor y amicicia de Alfonso Fernández de Madrigal ${ }^{19}$, dirigido a Juan II de Casti1la. Dentro del conjunto de testimonios romanzados, cabría diferenciar dos grandes ramas. En primer lugar, la traducción de la Genealogía realizada por Villafuerte, acompañada de sus glosas $\left(\mathrm{E}^{2}, \mathrm{~N}^{6}, \mathrm{~N}^{5}, \mathrm{R}^{1}\right)^{20}$, con la excepción del testimonio $\mathrm{P}$, que prescinde de las mismas ${ }^{21}$. Cabe señalar que un testimonio $\left(\mathrm{R}^{2}\right)$ ha transmitido la suplicación y razonamiento del trasladador Juan de Villafuerte y de una forma fragmentaria algunas de sus adiciones o glosas. En segundo lugar, las versiones sumarias de la Genealogía, con $\mathrm{E}^{1}$ como el testimonio más antiguo, del cual derivarían $\mathrm{N}^{8} \mathrm{y} \mathrm{N}^{9} 22$.

${ }^{15}$ BNE, Res. 35, ff. 12v-13r. Cfr. José L. Rodríguez Montederramo, art. cit., pp. 20-21.

${ }^{16}$ B. Esc., x-II-23, f. 197r. Es poco lo que se conoce de este traductor, citado en alguna ocasión como «Juan Çapata de Villafuerte, un cavallero de Salamanca en tiempo de los Reyes Cathólicos» (RAH, Salazar y Castro, N-24, f. 128r), referencia que ha de ser desechada por su carácter tardío. Parece más o menos cierta su vinculación con la ciudad de Salamanca y su condición de caballero y miembro del famoso linaje de los Villafuerte. En este sentido, dicho personaje probablemente habría de identificarse con Juan de Villafuerte o Juan Rodríguez de Villafuerte ( $†$ 1514), tercer señor de Villafuerte, regidor de Salamanca $(1473,1478)$, hijo de Juan Rodríguez de Villafuerte (†ca. 1446) y de doña Aldonza Rodríguez, casado con doña Inés Solís y hermano del también regidor Gonzalo de Villafuerte. José Sánchez Vaquero, Linajes de Salamanca, Salamanca, Universidad Pontificia, 2001, pp. 218-219.

${ }^{17}$ José L. Rodríguez Montederramo, art. cit., pp. 19, 21.

${ }^{18}$ Por ejemplo, BNE, ms. 815, f. 175r; BNE, ms. 9436, ff. 195r-196r; B. Esc., x-II-23, ff. 196v-197r.

${ }^{19}$ Alonso de Madrigal, Breviloquio de amor y amicicia, RAH, 9/2544, p. 1.

${ }^{20}$ Entre estos testimonios, $\mathrm{R}^{1}$ y $\mathrm{E}^{2}$ muestran una dependencia directa, pues ambos incluyen igualmente glosas coincidentes (por ejemplo, en $\mathrm{R}^{1}$, f. $10 \mathrm{r}$ y E $\mathrm{E}^{2}$, f. 10r; R ${ }^{1}$, f. $193 r$ y E ${ }^{2}$, ff. 193v-194r; $\mathrm{R}^{1}$, ff. 196v-197r y $E^{2}$, f. 197r-v), que no aparecen en otros testimonios (por ejemplo, en $\mathrm{N}^{6}$ ). Algunas de estas glosas serían anteriores a 1473, pues en una de ellas se hace referencia al almirante don Fadrique ( $\dagger 1473)$, «que agora es, al tiempo del rey don Enrique Quarto», RAH, 9/5573, f. 193r. A su vez, $\mathrm{N}^{5}$ guarda una estrecha relación con $\mathrm{E}^{2}$, pues ambos incluyen una glosa $\left(\mathrm{E}^{2}\right.$, f. $197 \mathrm{r}-\mathrm{v}$ y $\mathrm{N}^{5}$, f. 196r-v) a la datación astrológica que ofrece Villafuerte de su traducción, copiando ambos, a su vez, unos Anales desde la Anunciación a la Virgen hasta el año 1475 y un Sumario de la crónica de los Reyes Católicos.

${ }^{21}$ Cabe indicar que el testimonio $\mathrm{N}^{7}$ es una traducción tardía, probablemente realizada en el siglo XVIII. Elisa Ruiz García, «El sueño...», p. 10; Íd., «Avatares...», p. 304.

${ }^{22} \mathrm{El}$ testimonio $\mathrm{N}^{9}$ tiene un carácter tardío, siendo fechable probablemente en el siglo XVII. Dicho testimonio lleva a cabo ligeras modificaciones en el texto, dirigidas principalmente -aunque se realice 


\section{El programa iconográfico conforme al diseño de Alonso de Cartagena: texto, imagen y ars memoriae en la Castilla del cuatrocientos}

El interés de Alonso de Cartagena por la retención en la memoria de los contenidos de la Genealogía es fundamental a la hora de comprender su estructura y programa iconográfico ${ }^{23}$. En este sentido, bajo esta directriz cabe entender, en primer lugar, la estructura invariable de cada una de las semblanzas regias (descripción del reinado, depingitur o indicación iconográfica, y concurrentia o cronología paralela de papas, emperadores, reyes de Francia y obispos de Burgos). En segundo lugar, el interés por el principio de brevedad que, aunque no sería ajeno a un tópico habitual en la literatura bajomedieval, se podría conectar de una forma directa con las estrategias dirigidas a facilitar la memorización ${ }^{24}$, en línea con los postulados de Hugo de San Víctor ${ }^{25}$ o del propio Alonso de Cartagena ${ }^{26}$. Por último y como aspecto que confiere una especificidad a la obra, las indicaciones textuales destinadas a diseñar un programa iconográfico. Probablemente, la familiaridad de Cartagena con el uso de la imagen en los medios eclesiásticos, su contacto directo con realidades artísticas foráneas, fruto de sus viajes fuera de la Península ${ }^{27}$, y la habitual presencia de la imagen en las genealogías podría explicar, en el marco de estas estrategias de la memoria, la disposición de dicho programa iconográfico.

El interés por la retención en la memoria de los contenidos de la Genealogía se enmarcaría en el conocido como ars memoriae, orientado al uso de un conjunto de recursos y de estrategias mnemotécnicas basadas en la ubicación de imágenes intelectuales (imagines), que sintetizarían la materia a recordar,

alguna adición ocasional- a su simplificación y a la modernización de su redacción. Cfr. Carmen Crespo Tobarra; Carmen Caro Jaureguialzo, Nuevos ingresos de manuscritos en la Biblioteca Nacional (mss. 22431-22608), Madrid, Biblioteca Nacional, 1994, p. 120.

${ }^{23}$ El papel de la memoria en relación con la Genealogía ha sido puesto de relieve por Luis Fernández Gallardo, «Idea...», pp. 329-330 y Rosa M. ${ }^{a}$ Rodríguez Porto, art. cit., p. 230. Sin deseo de ofrecer una relación exhustiva, son de interés sobre la dimensión mnemotécnica de la imagen: John B. Friedman, «Les images mnémotechniques dans les manuscrits de l'époque gothique», en Jeux de mémoire: aspects de la mnémotechnie médiévale, Montreal; París, Presses de l’Université de Montréal; J. Vrin, 1985, pp. 169-184; Frank Willaert et al. (eds.), Medieval Memory. Image and Text, Turnhout, Brepols, 2004, pp. 129-143; Lina Bolzoni, «The Play of Memory Between Words and Images», en Memory and Oblivion, Dordrecht, Springer Netherlands Imprint, Springer, 1999, pp. 11-18.

${ }^{24}$ Luis Fernández Gallardo, Alonso..., p. 290; Íd., «Idea...», p. 327.

${ }^{25}$ Mary Carruthers, The Book of Memory: a Study of Memory in Medieval Culture, Cambridge; Nueva York, Cambridge University Press, 2008, p. 79.

${ }^{26}$ Alfonso de Cartagena, Memorial de virtudes, ed. de Mar Campos Souto, Burgos, Ayuntamiento de Burgos, 2004, epílogo, p. 449.

${ }^{27}$ Sobre este aspecto es fundamental el trabajo de Pilar Silva Maroto, «Arte y sociedad en el siglo Xv. Las promociones artísticas de Alonso de Cartagena (1440-1456)», en Enea Silvio Piccolomini, Roma, Libreria Editrice Vaticana, 2007, pp. 33-55. 
en un conjunto de lugares mentales (loci), que actuarían a manera de espacios ordenadores de dichas imágenes. Estos recursos, relacionados con el uso de la memoria artificial, habían sido desarrollados, en el marco de la retórica clásica, principalmente por los tratados De oratore (lib. II, 350-360) de Cicerón, Institutio oratoria (lib. XI, cap. II) de Marco Fabio Quintiliano y la pseudo-ciceroniana Rhetorica ad Herennium (lib. III) ${ }^{28}$, obra esta última que adquirirá una especial difusión en la Edad Media, siendo conocida en la península ibérica, al menos, desde el siglo $\mathrm{XIV}^{29}$. En su transmisión medieval, el ars memoriae se desvinculó progresivamente de la retórica, para definir, a fines de la Edad Media, un conjunto de técnicas que servían, en palabras de Paolo Rossi, como «ayuda para quienes se ocupan en actividades civiles» ${ }^{30}$.

En el contexto de este ars memoriae, la incorporación de la imagen a la Genealogía se relacionaría con la denominada como memoria rerum, es decir, con la memorización de los temas principales de un texto, asociado cada uno de ellos a una imagen sumaria ${ }^{31}$. En este sentido, como el propio Alonso de Cartagena señalaría, conforme a la traducción de Villafuerte:

Mas por cuanto las imágines de las cosas a la memoria más fuertemente ayudan que la desnuda escriptura, conveniblemente essos mismos reyes en logar de árbol fize pintar (f. 6v).

Este interés por las imágenes guardaría así una estrecha relación con las estrategias de la memorización, pues estas ayudarían a la creación de las referidas imágenes intelectuales. Conforme a los postulados de De oratore de Cicerón y de la Rhetorica ad Herennium, la novedad y las realidades sobresalientes y excepcionales -por su belleza, como la adición de coronas; por su fealdad, como la presencia de sangre; o por su efecto cómico- tendrían la capacidad de conmover, condición necesaria para quedar grabadas en la memoria $^{32}$. La estrategia de recurrir a la imagen como instrumento de la memoria artificial adoptada por Cartagena era, en esencia, la misma que seguiría

\footnotetext{
${ }^{28}$ Sobre este contexto de la arquitectura mnemotécnica, la nmemotecnia ciceroniana o el arte de la memoria en época medieval, véase: Mary Carruthers, ob. cit., pp. 71-79.

${ }^{29}$ Salvador Núñez, «Introducción», en Retórica a Herenio, ed. de Salvador Nuñez, Madrid, Editorial Gredos, 1997, pp. 7-59, pp. 42-43.

${ }^{30}$ Paolo Rossi, Clavis universalis. El arte de la memoria y la lógica combinatoria de Lulio a Leibniz, México D.F., Fondo de Cultura Económica, 1989, p. 42.

${ }^{31}$ Mary Carruthers; Jan M. Ziolkowski, The Medieval Craft of Memory. An Antology of Texts and Pictures, Filadelfia, University of Pennsilvana Press, p. 10; Mary Carruthers, ob. cit., p. 73.

${ }^{32}$ Rhetorica ad Herennium, ed. de Juan Francisco Alcina, Barcelona, Bosch, 1991, lib. III, XXII, pp. 222-225; Cicerón, De oratore. 1, Books I, II, ed. de E.W. Sutton, Londres; Cambridge, William Heinemann; Harvard University Press, 1967, lib. II, 358, pp. 468-471. Cfr. Mary Carruthers; Jan M. Ziolkowski, ob. cit., p. 13; Mary Carruthers, ob. cit., pp. 144, 245, 257.
} 
Pedro Núñez de Osma para diseñar el programa iconográfico de su Suma de virtuoso deseo ${ }^{33}$ y la defendida por Juan Alfonso de Benavente en su Ars et doctrina studendi et docendi (1453) ${ }^{34}$.

A su vez, la presencia de la imagen podría relacionarse, en estrecha relación con la memoria, con la propia idea de brevedad, por cuanto la imagen era considerada como un instrumento coadyuvante a la síntesis, fundamental para facilitar, como mencionamos, los procesos de memorización. Aunque Cartagena no es explícito en este sentido, se trataría de una idea presente en otras obras de fines de la Edad Media, como, por ejemplo, el citado pasaje de la Suma de virtuoso deseo de Pedro Núñez de Osma ${ }^{35}$ o el proemio de la Crónica de Fernán González de fray Gonzalo de Arredondo ${ }^{36}$, coherente con la perspectiva presentada por el clérigo francés Hugo de Folieto, quien en relación con las imágenes emplearía el verbo descrecere (disminuir en tamaño), o sea, la reducción de la prolijidad a la brevitas a través de la imagen ${ }^{37}$.

Aunque el hecho de concebir un programa iconográfico para una obra manuscrita no constituía, en modo alguno, una novedad en el ámbito castellano, sí lo eran las indicaciones textuales dirigidas a orientar dicho programa. No por el hecho mismo de consignarlas por escrito, pues tales apuntes, destinados a los iluminadores, generalmente situados en los márgenes del folio, serán habituales en el Occidente medieval ${ }^{38}$-sin ir más lejos, el Libro del cavallero Zifar (Bibliothèque Nationale de France, Espagnol 36) conserva algunas de estas indicaciones iconográficas ${ }^{39}$-, sino por incluirlas en el propio cuerpo del texto de forma pormenorizada y sistemática ${ }^{40}$, y por encontrarse dirigidas no solo al miniaturista, sino probablemente también al lector. Así,

${ }^{33}$ «E porque ayan más breve enformación los que en esta dicha suma leyeren, puse la figura de cada un señor, rey e emperador, porque vista su figura traiga a la memoria sus fechos e virtudes», BNE, ms. 1518 , f. $27 \mathrm{v}$.

${ }^{34}$ Bernardo Alonso Rodríguez, «Arts et doctrina studendi et docendi», en Salmanticensis, XIX:1 (1972), pp. 5-105, parte I, cap. V, pp. 86-87.

${ }^{35} \mathrm{BNE}, \mathrm{ms} .1518$, f. $27 \mathrm{v}$.

${ }^{36}$ «Y después los que d'él proceden por la misma vía, copilando y passando brebemente sus istorias, figurando y debuxando sus insignias y personas», RAH, 9/2047, f. 3v.

${ }^{37}$ Mary Carruthers, ob. cit., p. 242.

${ }^{38}$ Lucien Febve; Henri-Jean Martin, La aparición del libro, México D.F., Fondo de Cultura Económica, 2005, p. XXXVI; Jonathan J.G. Alexander, Medieval Illuminators and Their Methods of Work, New Haven; Londres, Yale University Press, 1992, pp. 54-63.

${ }^{39}$ José Manuel Lucía Megías, «El Libro del cavallero Zifar ante el espejo de sus miniaturas: la jerarquía iconográfica del ms. esp. 36 de la Bibliothèque Nationale de France», en El libro y sus públicos, Madrid, Ollero y Ramos, 2007, pp. 43-77, pp. 52-54.

${ }^{40}$ No obstante, este aspecto no es un caso único en el contexto europeo, pues se conocen indicaciones textuales señalando la temática de las imágenes, en unas ocasiones de una forma detallada y, en otras, de una forma más breve, a modo de rúbricas o de textos prologales. Jonathan J.G. Alexander, ob. cit., pp. 53-54. 
dichas indicaciones ofrecerían a este último las claves iconográficas para interpretar la imagen que estaba contemplando y, a su vez, le permitirían reforzar la memoria artificial, a través de la imagen mental creada a partir de la lectura de tales indicaciones iconográficas ${ }^{41}$. Dicho aspecto explicaría, al menos, parcialmente, el hecho de que estas orientaciones se hayan conservado en aquellos ejemplares de la Genealogía que, como los impresos o el testimonio $\mathrm{N}^{3}$, prescindieron del aparato iconográfico.

La orientación ideológica del programa iconográfico diseñado por Cartagena nos es bien conocida gracias a la aportación de Luis Fernández Gallardo, quien ha señalado el papel que tendría la fortitudo como elemento central de dicho programa, en conexión con la misión religiosa atribuida a la realeza castellana en la lucha contra el Islam ${ }^{42}$. A la hora de planificar el diseño iconográfico, Cartagena procedió a la jerarquización de los personajes representados a través de la figuración completa o parcial de los mismos (ff. 6v-7r). Dicha formulación tendría probablemente su origen en algunas genealogías que, al menos, desde inicios del siglo XIV -creación que Marigold A. Norbye atribuye a Bernard $\mathrm{Gui}^{43}$ - habrían diferenciado entre los miembros de la línea genealógica principal, representados de cuerpo entero, y los personajes secundarios, figurados a través de sus efigies, ambos con sus correspondientes atributos identificativos ${ }^{44}$. En este sentido, Cartagena buscaría sintetizar visualmente algunos aspectos de la correspondiente semblanza a través de motivos concretos (indumentaria, circunstancias de la muerte, etc.), que se presentarían, en línea con lo indicado por la Rhetorica ad Herennium ${ }^{45}$, como clave para recordar aspectos diversos del texto.

Alonso de Cartagena se mueve, en lo que toca al diseño de su obra, entre lo textual y lo visual, específicamente en lo que se refiere a la imagen del árbol, asumido por la literatura genealógica para la representación diagramática de las relaciones entre los distintos miembros de una familia. En este

${ }^{41}$ La misma teoría, es decir, que las indicaciones iconográficas se encuentran dirigidas al lector, ha sido apuntada por Luis Fernández Gallardo, atendiendo al uso de la fórmula depingitur. Luis Fernández Gallardo, «Idea...», p. 333. Para una contextualización de esta serie de aspectos relativos al papel de la imagen, la lectura y la memoria, en torno a la creación de imágenes mentales, son de especial interés los apuntes de Mary Carruthers, ob. cit., pp. 221-257.

${ }^{42}$ Luis Fernández Gallardo, «Idea...», pp. 329-353, especialmente pp. 349-351, con algunas indicaciones complementarias en Elisa Ruiz García, «El sueño...», pp. 12-13; Id., «Avatares...», pp. 310-311.

${ }^{43}$ Marigold Anne Norbye, «Arbor...», p. 80.

${ }^{44}$ Por ejemplo: De origine prima francorum, BNE, ms. 10126, ff. 147r-214r; Genealogical Chronicle of the English Kings, British Library, 14 B. vi.; De Origine prima Francorum, Bibliothèque Municipale de Toulouse, ms. 450; Bernard Gui, Arbor genealogie regum Francoum, Bibliothèque Nationale de France (BNF), Lat. 4975; Bernard Gui, Arbre de la genealogie des rois des Francs, BNF, Lat. 4989; Genealogical History of the Kings of England, HL, Typ. 11.

${ }^{45}$ Rhetorica ..., lib. III, XX, pp. 218-221. 
sentido, esta imagen del árbol servirá como figura para aludir a algunas de las tareas propias de la actividad historiográfica de Cartagena, sea esta la reformulación del proyecto, a través de la metáfora del árbol que es trasplantado (f. 6r), o la propia disposición del texto, en un diseño de página que parece ser asimilado a un árbol, en el cual la caja de escritura se equipararía al tronco, espacio donde se representarían las imágenes de los reyes (f. 6v). En este sentido, aunque Cartagena parte de la imagen visual del árbol, el discurso que despliega es, ante todo, verbal. En este sentido, el obispo de Burgos piensa con frecuencia en términos visuales y parece percibir su obra como un árbol genealógico en el que lo visual y lo textual alcanzan una unidad significativa, sin que la dimensión diagramática tuviera necesariamente una materialidad real, como veremos a continuación. Ello hubo de llevar a que Villafuerte tradujese el término latino arbor como tabla $^{46}$ (f. 30r), cuyo significado, aunque difícil de establecer con precisión, se podría acercar a la definición tardía de «lista o catálogo de algunas cosas puestas por orden sucesivo» ${ }^{47}$, o que recurriera, a la hora de realizar la traslación de la Genealogía, a fórmulas como «fezimos mención en el árbol» (f. 99v) o «segúnt el discurso del árbol mostrará» (f. 142r).

\section{El programa iconográfico: los testimonios iluminados de la Genealogía de los reyes de España}

Desconocemos si pudo existir un arquetipo iluminado realizado bajo las directrices directas del obispo de Burgos. En cualquier caso, lo único que es posible afirmar con cierta seguridad es que los testimonios en apariencia más antiguos $\left(\mathrm{A}, \mathrm{N}^{1}, \mathrm{~N}^{2}\right)$ reservarían un espacio para la imagen correspondiente -imágenes que nunca se llegaron a ejecutar-, siguiendo una disposición texto-imagen más propia de las crónicas ilustradas que de las genealogías. Este hecho permite sugerir, en línea con lo dicho anteriormente, que probablemente la estructura que Cartagena tenía ideada para su Genealogía se asemejaría a esta disposición -como muestran las referencias que hace el obispo de Burgos a la ubicación de las imágenes in rectitude arboris ${ }^{48} \mathrm{o}$ in

${ }^{46}$ «Sequitur radix arboris in Athanarico rege gothorum», HL, Typ. 162, f. 13r, traducido como «Síguese la principal tabla de los reyes», BNE, ms. 815, f. 16r.

${ }^{47}$ Diccionario de la lengua castellana, Madrid, Imprenta de la Real Academia Española, por los Herederos de Francisco del Hierro, 1739, t. VI, p. 204.

${ }^{48}$ Alonso de Cartagena, «Regum Hispanie Anacephelosis», en Hispaniae illustratce, Fráncfort, Claudium Marnium, \& Hæredes Iohannis Aubrij, 1603, t. I, pp. 246-291, pp. 271, 275, 279. 
recta linea arboris ${ }^{49}$ e in margine $e^{50}$ o in later $^{51}-$, antes que a la representación iconográfica ordinaria de los árboles genealógicos, basada en el uso de diagramas. La disposición de $\mathrm{A}$ y de $\mathrm{N}^{1}$ permite sugerir que, conforme al proyecto ideado por Cartagena o su entorno, la imagen se ubicaría al inicio de cada semblanza. No obstante, la primera mano que realizó los dibujos del testimonio A alteró esta disposición, al situar los dibujos al final de las correspondientes semblanzas, en una disposición que sería adoptada posteriormente en el testimonio $\mathrm{P}$.

En la actualidad, se conocen cuatro testimonios de la Genealogía (A, P, $\mathrm{E}^{1}, \mathrm{~N}^{4}$ ) que desarrollan, desde diferentes aproximaciones, el programa iconográfico diseñado por Alonso de Cartagena.

\subsection{El testimonio A [AHN, CC, 983]}

El testimonio latino A probablemente sea el más antiguo de los ejemplares iluminados de la Genealogía $a^{52}$. Siguiendo lo indicado por Elisa Ruiz, parece posible suponer una vinculación de este códice, atendiendo a sus rasgos paleográficos y abreviaturas (§ III. La recepción de la Genealogía de los Reyes...), con el entorno de Alonso de Cartagena. De allí, hipotéticamente hubo de ser remitido a la corte de Enrique IV, como permite sugerir, como veremos a continuación, su programa iconográfico. En algún momento, antes, en cualquier caso, de 1627, el códice debió de llegar a Sevilla, donde hubo de ser consultado por el teólogo Juan de Pineda (1557-1637) en el colegio de la Concepción de la Compañía de Jesús ${ }^{53}$, de cuya biblioteca hubo de formar parte hasta $1767^{54}$, cuando, con motivo de la supresión de la Compañía, esta se dispersó ${ }^{55}$. En una fecha seguramente no lejana a 1767, Gaspar Melchor de

${ }^{49}$ Ibidem, pp. 275, 281.

${ }^{50}$ Ibídem, pp. 260, 263, 265, 268-279, 283-289.

${ }^{51}$ Ibidem, pp. 259, 272, 280, 282-283.

${ }^{52}$ Elisa Ruiz García, «Avatares...», p. 300; José L. Rodríguez Montederramo, art. cit., p. 17.

${ }^{53}$ Juan de Pineda, Memorial de la excelente santidad y heroycas virtudes del señor rey don Fernando, Sevilla, Oficina de Matías Clavijo, 1627, p. 181 e Índice de Autores, $n^{\circ}$ 11, s. f. El testimonio A sería seguramente el mismo ejemplar consultado por Pineda, si atendemos a su incipit, a sus características paleográficas y a su extensión.

${ }^{54}$ En este sentido, solo parece parcialmente correcta la información consignada al inicio del códice por Aureliano Fernández-Guerra y Orbe, con fecha de 28 de abril de 1883, en la que indica que «este códice perteneció al Colegio de la Compañía de Jesús de la ciudad de la Concepción, en Chile; hízose de él Jovellanos en Sevilla, y me le regala hoy mi cariñoso y docto amigo el Vice-Rector de la Universidad de Oviedo, Sr. D. Fermín Canella Secades», AHN, CC, Lib. 983, portada. Es probable que esta referencia al «Colegio de la Compañía de Jesús de la ciudad de la Concepción» proceda de una lectura errónea de la nota manuscrita «Del Collegio de la Comp. de Jesús de la Concepción de Sevil.», AHN, CC, Lib. 983, f. 1r.

${ }^{55}$ Antonio Martín Pradas; Inmaculada Carrasco Gómez, «El colegio de la Inmaculada Concepción de la Virgen María, Nuestra Señora, de la Compañía de Jesús de Sevilla, vulgo de las Becas (1598-1634)», en Atrio, 12 (2006), pp. 71-80, p. 79. 


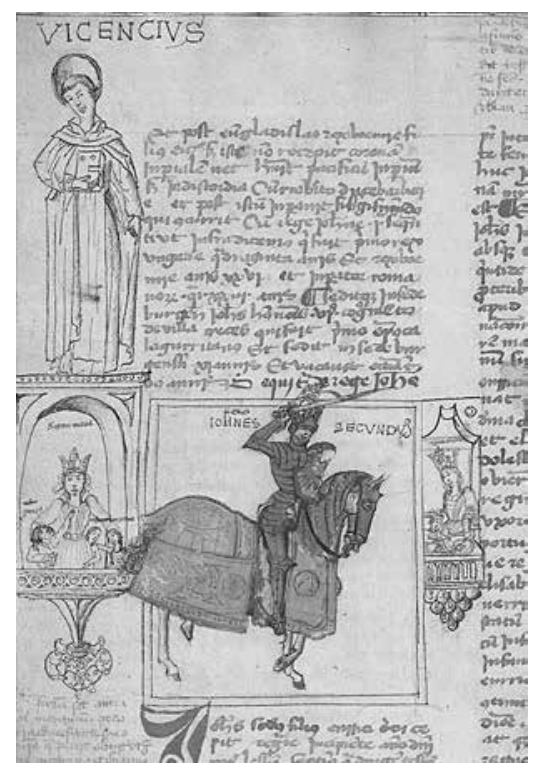

Fig. 1. Juan II de Castilla. Alonso de Cartagena, Arbor genealogie regum Hispanie, AHN, CC, Lib. 983, f. 43v. Reproducido en Elisa Ruiz García, «El sueño de la edición múltiple: unos testimonios tempranos», en Pliegos de Bibliofilia, 8 (1999), pp. 5-24, p. 15, doc. 4.
Jovellanos (1744-1811), quien ocuparía a partir de 1768 una plaza de alcalde del crimen en la Real Audiencia de Sevilla ${ }^{56}$, hubo de adquirirlo en la ciudad. Posteriormente, el códice hubo de pasar a manos del vicerrector de la Universidad de Oviedo, Fermín Canella Secades (1849-1924), quien lo regaló en abril de 1883 a Aureliano Fernández-Guerra y Orbe (1816-1894). Finalmente, en una fecha indeterminada, el códice ingresó en la sección Diversos del Archivo Histórico Nacional, pasando en octubre de 1964 a la colección de Códices y Cartularios del mismo archivo ${ }^{57}$.

Dentro de su programa iconográfico sería posible diferenciar, de manera provisional, tres $\operatorname{manos}^{58}$ : una primera (ff. 8v-14v), correspondiente a un dibujante castellano, caracterizado por su trazo seguro, que, aunque no parece ajeno por completo a las influencias nórdicas, se encontraría apegado a modelos figurativos tradicionales, con tipos iconográficos característicos como el rey entronizado. Cabría situar cronológicamente estos dibujos, como bien indica David Chao Castro, atendiendo a la granada incorporada al tocado de Leovigildo (f. 12r), durante el reinado de Enrique $\mathrm{IV}^{59}$. Una probable segunda mano, que muestra calidades desiguales en el trazo del dibujo (ff. $14 \mathrm{r}-14 \mathrm{v}, 15 \mathrm{v}-21 \mathrm{v}, 22 \mathrm{v}$, probablemente la figura inacabada de Gaudiosa y la corona de don Pelayo en f. 23r, y los dibujos de los ff. 43v y 45v, correspondientes a Juan II (fig. 1) y Enrique IV de Castilla, policromados quizá en deferencia a ambos reyes). Esta mano sería posterior a la primera, pudiéndose datar, en cualquier caso, en el tercer cuarto del siglo Xv, con estrechos paralelos, aunque de una calidad inferior, con la

${ }^{56}$ Manuel Álvarez-Valdés y Valdés, Jovellanos: vida y pensamiento, Oviedo, Ediciones Nobel, 2012, pp. 51-62.

${ }^{57}$ AHN, CC, Lib. 983, s. f.

${ }^{58}$ David Chao Castro, ob. cit., pp. 250-251, 384, lleva a cabo la identificación de dos manos, al igual que Elisa Ruiz García, «Avatares...», p. 311.

${ }^{59}$ David Chao Castro, ob. cit., p. 392. 
iconografía del testimonio $\mathrm{P}^{60}$. Estos dos primeros dibujantes cabría situarlos con seguridad durante el reinado de Enrique IV, quizás en el entorno de la corte regia. Es probable que, a la hora de diseñar este programa, ambos dibujantes tuvieran como referente estético e iconográfico alguna de las imágenes del testimonio $\mathrm{E}^{161}$. Por último, una tercera mano (la figura masculina de $\mathrm{f}$. 23r y f. 43r), posterior en el tiempo y de escasa calidad.

Al final del códice, se dispone un diagrama final, cuyo diseño recordaría a los roleos vegetales de las orlas marginales de influencia nórdica de mediados del siglo XV, en cuyo interior se situarían los nomina regum (ff. 46r-50v), siguiendo la relación de reyes del Arbor genealogie regum del testimonio $\mathrm{N}^{1}$ (f. 74r). Este diagrama hubo de ser realizado en el tercer cuarto del siglo Xv -aunque se completaría en un momento posterior, en una letra humanística muy cursiva, hasta el rey Felipe II (1556-1598)-, atendiendo al hecho de que dicho diagrama finalizaría con Enrique IV, «que hodie rregnat» (f. 50v). En los trazos del diagrama podríamos diferenciar dos manos: una primera (ff. 46r-47r), de condición un tanto tosca, y una segunda (ff. 47v-50v), con un aire más grácil y un diseño formal más cercano -aunque simplificado-al testimonio P. Cabe señalar que los nonima regum del diagrama fueron escritos por una mano diferente a la que redactó el texto de la Genealogía, lo que permite sugerir que este diagrama hubo de ser realizado en un momento posterior al texto, seguramente en el marco de la ejecución del programa iconográfico.

En este sentido, el códice quizá pudo constituir un primer intento por dotar, en el entorno de la corte regia, de un programa iconográfico a la Genealogía, pronto abandonado en favor de un nuevo proyecto: el testimonio $\mathrm{P}$.

\footnotetext{
${ }^{60}$ Sobre este aspecto llamaron la atención David Chao Castro, ob. cit., p. 325, quien indica que el testimonio A sería «el punto de partida y fuente iconográfica directa para la del Palacio Real», y Elisa Ruiz García, «Avatares...», p. 312. Cabe destacar, junto a la indumentaria de influencia borgoñona, el vestido de Gaudiosa (f. 23r) - una saya con trena, similar a la indumentaria de una imagen del coro de la catedral de León, que Carmen Bernis data hacia 1467-, que situaría esta segunda mano en la década de 1460. Cfr. Carmen Bernis, Indumentaria medieval española, Madrid, Instituto Diego de Velázquez, 1956, lám. 39, figs. 135-136.

${ }^{61}$ En este sentido, querríamos llamar la atención sobre el posible paralelo existente, por un lado, entre la imagen grabada del rey armado, con armadura, espada y estandarte, del testimonio $\mathrm{E}^{1} \mathrm{y}$ la figura de Alarico, realizada por la primera mano, en AHN, CC, Lib. 983, f. 9r, en lo que respecta al diseño general de la imagen. Por otro lado, entre la imagen grabada del rey pacífico, con vestidura y espada en la mano, del testimonio $\mathrm{E}^{1}$ y la correspondiente a Liuva I, primer dibujo que confeccionó la segunda mano, en AHN, CC, Lib. 983, f. 14r, en lo que se refiere al planteamiento estético general, la posición del cuerpo, el marco romboidal, reflejado en el testimonio $\mathrm{A}$ en las dos secciones triangulares en las esquinas superiores del marco, que imitarían yeserías, y la posición del pie izquierdo, que sale del marco.
} 


\subsection{El testimonio $P[R B, I I / 3009]$}

Este testimonio, que incorpora un total de 82 dibujos a pluma ${ }^{62}$, cabría situarlo aproximadamente hacia 1464-1470, atendiendo a la fecha de finalización de la traducción de Villafuerte y a la datación que ofreció Carmen Bernis de las modas en él representadas, fechadas en torno a $1460^{63}$.

El ejemplar $\mathrm{P}$ ha sido considerado en alguna ocasión como un códice probablemente realizado para Enrique IV ${ }^{64}$. La autoría de los dibujos ha sido revisada recientemente, habiendo apuntado verosímilmente Isabel Mateo Gómez, como probable autor de los mismos, a Jorge Inglés, sin descartar la participación, como colaborador, del Maestro de Sopetrán ${ }^{65}$. En este sentido, el testimonio P muestra una deuda a nivel formal -en cualquier caso, coherente con el estilo de Jorge Inglés, del que indica Pilar Silva Maroto que hubo de conocer algunas obras de la escuela de Tournai ${ }^{66}$ - con la miniatura de los antiguos Países Bajos meridionales, que marcaría las producciones contemporáneas que se estaban realizando en la corte del duque de Borgoña, Felipe el Bueno (1419-1467), de la mano de miniaturistas como Jean Le Tavernier o Jean Miélot ${ }^{67}$. De aceptar que el códice pudo ser realizado para Enrique IV, en esta elección hubo de pesar no solo el interés regio por la estética nórdica en el campo de la iluminación de manuscritos, manifestado en el referido códice del Libro del cavallero Zifar, sino también la influencia, a través del testimonio A, del modelo iconográfico de $\mathrm{E}^{1}$. En este sentido, cabría llamar la atención sobre algunas conexiones estilísticas de la Genealogía con este ámbito neerlandés, como: el canon corporal, caracterizado por la proporción

${ }^{62} \mathrm{El}$ códice ha sufrido la sustracción de algunos folios, con la desaparición de los dibujos correspondientes a Alfonso VI y a Juan II de Castilla, como han apuntado Elías Tormo, ob. cit., p. 235 y Ramón Menéndez Pidal, Crónicas generales de España, Madrid, Real Biblioteca, 1918, p. 131.

${ }^{63}$ Carmen Bernis, ob. cit., lám. 39, fig. 155.

${ }^{64}$ Fernando Villaseñor Sebastián, El libro iluminado en Castilla durante la segunda mitad del siglo ${ }_{X V}$, Salamanca; Segovia, Instituto Castellano y Leonés de la Lengua; Caja Segovia, 2009, p. 104; David Chao Castro, ob. cit., pp. 244-245; Josefina Planas Badenas, «El manuscrito de París. Las miniaturas», en Libro del caballero Zifar. Códice de París. Vol. II: Estudios, Barcelona, Moleiro, 1996, pp. 137-92, pp. 142, 191. Recientemente Isabel Mateo Gómez ha considerado la posibilidad de que el destinatario fuera Alonso de Cartagena o Íñigo López de Mendoza en Isabel Mateo Gómez, ob. cit., p. 20, aunque la datación del códice arriba apuntada lo alejaría cronológicamente de ambos personajes.

${ }^{65}$ Ibidem, pp. 21-33, 54-59.

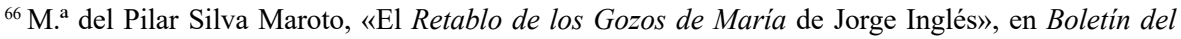
Museo del Prado, 48 (2012), pp. 6-23, p. 11.

${ }^{67}$ Sobre los problemas que plantea la caracterización de lo borgoñón desde el punto de vista de la miniatura, véase Hanno Wijsman, «Bourgogne, bourguignon....Un style de manuscrits enluminés?», en La cour de Bourgogne et l'Europe: Le rayonnement et les limites d'un modèle culturel, Ostfildern, Jan Thorbecke Verlag, 2013, pp. 361-376. En lo que se refiere a la denominación de antiguos Países Bajos meridionales seguimos la denominación dada en Ilona Hans-Collas et al., Manuscrits enluminés des anciens PaysBas méridionaux. I, Manuscrits de Louis de Bruges, París, Bibliothèque Nationale de France, 2009, p. 9. 
esbelta de las figuras; el interés por las formas arquitectónicas para enmarcar las escenas; los usos de la perspectiva; la gestualidad corporal; la tipología de edificios, doseles, caballos, armaduras o escudos; el diagrama al final del códice (ff. 209r-210v), inspirado en los roleos vegetales de las orlas marginales emparentadas con lo nórdico; la articulación entre escenas principales y secundarias, que da lugar a una cierta complejidad compositiva -de las que son buena muestra, en el ámbito nórdico, impresos como la Biblia pauperum (ca. 1462) o las Horas al uso de Roma (1498), diseñadas por el Maestro de Ana de Bretaña-, con escenas laterales dispuestas a modo de balcones. Esta articulación alcanza su más alta complejidad en la figuración de las semblanzas de Leovigildo (f. 69r) y de Alfonso I (f. 112v), que adoptan la estructura de un retablo; y, por último, la estética cromática, por cuanto parece que el códice se encontraba destinado a ser pintado en grisalla, como sugieren las dos ilustraciones iniciales (ff. 39r, 43r), los sombreados y los rótulos en rojo. Una técnica que probablemente habría que conectar, en último término, con las nuevas tendencias difundidas a partir de 1440 en obras populares de carácter religioso en el norte de los Países Bajos y desde mediados de siglo en la corte del duque de Borgoña ${ }^{68}$, entre las cuales es posible destacar el conjunto de obras, realizadas en el entorno de Felipe el Bueno, caracterizadas por la ausencia de márgenes miniados y la disposición del texto a una columna ${ }^{69}$.

No obstante, existen algunos elementos que permiten sugerir que el miniaturista del testimonio $\mathrm{P}$ se encontraba en estrecho contacto con la realidad palatina y cortesana castellana del cuatrocientos. En este sentido, es posible llamar la atención sobre la representación de los frisos de yesería (ff. 52r, 74r), los arrimaderos de azulejería (ff. 56r, 63r), los arcos de herradura (f. $128 \mathrm{v}$ ) y el diseño de los tronos (especialmente ff. 39r, 45v, 159r, 194r), que guardan estrechos paralelos formales con los representados en las piezas numismáticas del período ${ }^{70}$. Entre estas representaciones, llama la atención el trono cubierto por un baldaquino de naturaleza arquitectónica del rey Chindasvinto (f. 86r), en relación con el cual es sugerente -aunque meramente

${ }^{68}$ Till-Holger Borchert, «Color lapidum: una aproximación a las representaciones en grisalla en la Baja Edad Media», en Jan van Eyck: Grisallas, Madrid, Museo Thyssen-Bornemisza, 2009, pp. 13-49, p. 46.

${ }^{69}$ Catherine Reynolds, «The Undecorated Margin: The Fashion for Luxury Books without Borders», en Flemish Manuscript Painting in Context. Recent Research, Los Angeles, J. Paul Getty Museum, 2006, pp. 9-27, pp. 13-15.

${ }^{70}$ Pensamos, por ejemplo, en los tipos 20.7, 20.8, 20.9, 20.10, 20.18, 20.19, 20.24, 20.25 sistematizados en Manuel Mozo Monroy; Manuel Retuerce Velasco, La moneda de oro en los Reinos de Castilla y León: siglos XII-XV, Madrid, NRT; Asociación española de arqueología medieval, 2010, pp. 102-113. 
hipotético- ver la influencia de los estalos del rey y la reina en el coro de la catedral de Segovia, realizados a lo largo de los años 1462 y $1463^{71}$.

Cabe destacar que los distintos personajes históricos aparecen representados bajo las modas adoptadas durante la década de los sesenta del siglo XV por las élites políticas de la Corona de Castilla, las cuales seguirían de cerca las novedades procedentes de la corte de Borgoña ${ }^{72}$. Es probable que dicha elección, más allá de la habitual traducción visual del pasado que tiene lugar en el arte medieval ${ }^{73}$, buscara ofrecer una imagen vivaz y dinámica de esta realeza histórica.

Junto a la indumentaria, el elemento más llamativo del proyecto son las grandes coronas y los tocados «colosales, diferentísimos, monumentales, estrambóticos», como los denominó Elías Tormo ${ }^{74}$. Su origen no cabe encontrarlo, como proponía Tormo, en el «teatro eclesiástico» ${ }^{75}$. En este sentido, probablemente quepa ver en ellos más bien una evocación de la suntuosidad del entorno regio, cuya puesta en escena tendría lugar con ocasión de la celebración de fiestas cortesanas o justas. Las coronas de gran tamaño, cuyos antecedentes inmediatos cabría probablemente encontrar en el testimonio A, vendrían a ofrecer una imagen deslumbrante de la realeza, a la vez que la amplificación visual de este atributo, realizada ocasionalmente bajo formas vegetales, enfatizaría la propia noción del oficio y de la soberanía regias. Los tocados de las reinas y otros personajes femeninos de la corte, adoptados bajo la influencia de las modas borgoñonas ${ }^{76}$, aparecen sobredimensionados bajo interpretaciones de naturaleza vegetal (granadas, flores, manojos de hierbas, piñas) o, más raramente, arquitectónica (mocárabes, agujas góticas). La atención hacia estos motivos vegetales, vinculados estrechamente a las fiestas de primavera $^{77}$, buscaría quizá, en coherencia con la orientación general del programa, incidir en la dimensión festiva y cortés del entorno regio, no siendo probablemente ajena, a su vez, a las ideas de generación y fertilidad del

\footnotetext{
${ }^{71}$ Archivo de la Catedral de Segovia, C-211, s. f. (00-VIII-1462; 15-III-1463).

${ }^{72}$ Sobre estas, véase Sophie Jolivet, Pour soi vêtir honnêtement à la cour de monseigneur le duc: costume et dispositif vestimentaire à la cour de Philippe le Bon, de 1430 à 1455, tesis doctoral inédita, Dijon, Université de Bourgogne, 2003.

${ }^{73}$ Anne D. Hademan, «Presenting the Past: Visual Translation in Thirteenth-to Fifteenth-Century France», en Imagining the Past in France. History in Manuscript Painting (1250-1500), Los Ángeles, J. Paul Getty Museum, 2010, pp. 69-85, con especial atención al papel de la indumentaria en ibídem, pp. 78-79.

${ }^{74}$ Elías Tormo, ob. cit., p. 222.

${ }^{75}$ Ibídem, p. 223.

${ }^{76}$ Sobre estos, véase: Hilda Amphlett, Hats. A History of Fashion in Headwear, Chalfont St. Giles (Buckinghamshire), Richard Sadler, 1974, pp. 55-62, con breve referencia a su recepción en el ámbito ibérico en Carmen Bernis, ob. cit., p. 52.

${ }^{77}$ Sobre la celebración de esta fiesta en la Corona de Castilla, véase: Miguel Ángel Ladero Quesada, Las fiestas en la cultura medieval, Barcelona, Debate, 2004, pp. 54-56.
} 
linaje regio, asociadas estrechamente tanto a las referidas fiestas de primavera como a los motivos vegetales y arbóreos ${ }^{78}$.

En su conjunto, la indumentaria, el dinamismo de las escenas en las que las figuras superan el marco de la representación, la interacción entre los personajes -en torno a los gestos de las manos, el contacto visual o las flores, que sirven como vía de relación galante entre las figuras representadas-, la inclusión de muertes violentas, enmarcadas por la tinta roja como representación de la sangre, y la presencia de ciertos detalles anecdóticos parecen ser un intento de atender a las recomendaciones del ars memoriae. Aunque sea imposible precisar hasta qué punto el iluminador conocía estos principios mnemotécnicos, es llamativo que con la figuración variada de los lugares donde se ubicaban las imágenes ${ }^{79}$, con la representación aislada de las mismas ${ }^{80}$ y con la introducción de variaciones iconográficas ${ }^{81}$, se facilitaba, conforme a los principios del ars memoriae, el funcionamiento de la memoria artificial.

A su vez, este programa parece estar dirigido a ofrecer una imagen magnificente y suntuosa de la corte regia, a través de una serie iconográfica atrayente caracterizada por una estética sugestiva, siguiendo el modelo de los manuscritos del entorno del referido duque de Borgoña. De hecho, parece que la estética y diseño del códice hubieron de ser una de las prioridades del proyecto, como permite sugerir el hecho de que se prescindiera de las glosas, quizá con el fin de dar realce a la imagen y asegurar un diseño visual adecuado.

Además de la ausencia de dichas glosas, este testimonio presenta algunas variantes, como es, en primer lugar, la alteración en el orden del capítulo LXIV (ff. 140r-141r), la eliminación en este de la indicación iconográfica relativa a Ruy Díaz de Vivar y la presencia de varios folios en blanco (ff. 145v-147r), seguidos de la figuración del citado Rui Díaz de Vivar (f. 147v). En segundo lugar, la adición de una extensa glosa, en f. 155v.

En la definición del programa iconográfico de $\mathrm{P}$, el testimonio A hubo de ser fundamental. No solo en relación con la segunda mano de A - ¿quizá la misma que realizó este testimonio P?- sino también con su primera mano, que sirvió como modelo iconográfico general de algunas figuras del testimonio P, como Atanarico I (f. 39r), Alarico (f. 43r), Sigerico (f. 45v), Turismundo (f. 50r) o Alarico II (f. 55r). Entre las representaciones iconográficas particulares de este testimonio cabe destacar ${ }^{82}$ : en primer lugar, la imagen

${ }^{78}$ En relación con la imagen del árbol, véase Christiane Klapisch-Zuber, art. cit., p. 437; Marigold Anne Norbye, «Arbor...», p. 90.

${ }^{79}$ Rhetorica ..., lib. III, XVI, p. 215; Ibídem, lib. III, XIX, p. 217.

${ }^{80} \mathrm{Ibidem}$, lib. III, XIX, p. 217.

${ }^{81}$ Ibídem, lib. III, XXII, p. 225

${ }^{82}$ Prescindimos de comentar las imágenes ya analizadas en Isabel Mateo Gómez, ob. cit., pp. 37-52. 


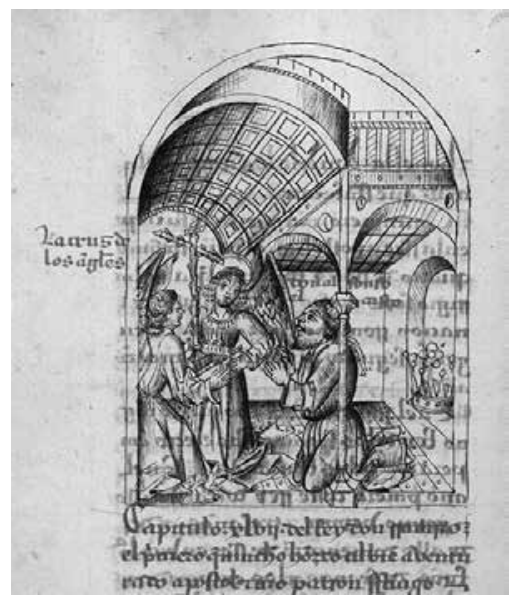

Fig. 2. Alfonso II el Casto. Alonso de Cartagena, Genealogía de los reyes de España, Real Biblioteca, II/3009, f. 119v. Reproducido en Isabel Mateo Gómez, Sobre el autor de los dibujos de la Genealogía de los Reyes de don Alonso de Cartagena, Burgos, Academia

Burgense de Historia y Bellas Artes; Institución Fernán González, 2005, p. 45.

de Recaredo II, un niño muerto a corta edad, que habría de estar representado, según Cartagena, «a ssemejança de moço en pueril vestidura» (f. 78r), figurado aquí como un infante sobre un león, muy similar al tipo iconográfico ampliamente difundido en el ámbito nórdico para la representación de san Adrián de Nicomedia ${ }^{83}$, quizás inspirado, en último término, en la figuración de los yacentes, a cuyos pies se situarían leones -especialmente en el caso de la realeza- $u$ otros animales ${ }^{84}$. En segundo lugar, las representaciones de Teodorico II (f. 58r) y de la entrega de la Cruz de los Ángeles a Alfonso II el Casto (f. 119v) (fig. 2). En ambas se romperían las pautas de representación habituales, tanto en lo que se refiere a los tipos fisionómicos como, en cierta medida, al marco arquitectónico, recordando lejanamente, de forma respectiva, a las imágenes de Alfonso X en la Estoria de España ${ }^{85}$ y en la General estoria ${ }^{86}$, ambas procedentes de la biblioteca del Marqués de Santillana y atribuidas por Francisco J. Sánchez Cantón a Jorge Inglés ${ }^{87}$; aspecto que quizá podría abrir nuevas vías para un mejor conocimiento del taller de miniatura del Marqués de Santilla y la problemática participación de Jorge Inglés en el mismo ${ }^{88}$. En tercer lugar, la representación de Atanagildo, en compañía de san Martín de Dumio y san Millán (f. 64v), y de Suintila, junto con san Eugenio y san Braulio (f. 82r), donde estos santos son figurados de manera abreviada por medio de una cabeza, siguiendo una fórmula de representación similar a la presente en el tema iconográfico de la Misa de san Gregorio. En quinto lugar, la imagen de Sancho III el Mayor sosteniendo

\footnotetext{
${ }^{83}$ Por ejemplo, en Nationale Bibliotheek van Nederland (NBN), 76 F 2, f. 297r; NBN, 10 E 4, f. 97r.

${ }^{84}$ Un buen ejemplo de esta transposición iconográfica se puede ver en Jean du Tillet, Recueil des rois de France, BNF, Français 2848 o en Alberto Durero, Study for a tomb, Oxford, Christ Church, JBS1422.

${ }^{85} \mathrm{BNE}, \mathrm{ms} .10134<3>$, f. $1 \mathrm{r}$.

${ }^{86}$ BNE, ms. 10236, f. 1r.

${ }^{87}$ Francisco Javier Sánchez Cantón, «Maestro Jorge Inglés, pintor y miniaturista del Marqués de Santillana (conclusión)», en Boletín de la Sociedad Española de Excursiones, XXVI (1918), pp. 27-31.

${ }^{88} C f r$. Joaquín Yarza Luaces, «La nobleza hispana y los libros iluminados (1400-1470). Corona de Castilla», en La memoria de los libros. Estudios sobre la historia del escrito y de la lectura en Europa y América, Salamanca, Instituto de Historia del Libro y de la Lectura, 2004, pp. 14-66, p. 28.
} 
sus armerías (f. 149r), en un modelo figurativo rígido y lejano del dinamismo habitual de otras imágenes, en el que cabría adivinar quizá una evocación de los tenantes de escudos. Por último, la figuración de Enrique IV (f. 205r), que podría relacionarse, como ya sugirió Elisa Ruiz, con las imágenes de Santiago matamoros $^{89}$.

Existen algunos elementos internos que permiten de forma provisional relacionar este códice con el entorno de la corte de Enrique IV: la estrecha relación con el ejemplar A, indicio del posible nexo de ambos con los talleres de iluminación de la corte, e indirectamente con el testimonio $\mathrm{E}^{1}$; la presencia que tiene el motivo de la granada (ff. 69r, 205r, más hipotéticamente en ff. $112 \mathrm{v}, 149 \mathrm{r}$ ), divisa del monarca ${ }^{90}$; el posible deseo, presente ya en el testimonio A, de eliminar en las escenas de las muertes regias a los magnicidas -excepción solo hecha con Enrique II de Castilla (f. 185v)-, como resultado de una cierta prevención, atendiendo al hipotético destinatario del códice, por parte del miniaturista; la propia ambición y calidad del proyecto; las modas reflejadas en el testimonio, que se incardinan en el ambiente aristocrático y cortesano; y el interés de Enrique IV por la genealogía ${ }^{91}$ y por dotarse de, al menos, dos manuscritos iluminados, confeccionados, según Lynette M. F. Bosch, por el taller de Juan de Carrión: el referido Libro del caballero Zifar y el Libro de la montería (Real Biblioteca, II/2105) ${ }^{92}$, siguiendo la inclinación de algunos nobles castellanos por los libros iluminados en los años finales del reinado de Juan $\mathrm{II}^{93}$.

En este sentido, atendiendo a la posible datación (ca. 1463-1470) y al hipotético destinatario del códice, parece sugerente relacionar este proyecto con la realización de la serie iconográfica dispuesta en la Sala de los Reyes del Alcázar de Segovia y el posible desarrollo, en el marco del conflicto de Enrique IV con parte de su nobleza, de estrategias de legitimación política centradas en la reivindicación de la legitimidad de origen de la monarquía y en la antigüedad del linaje real.

\footnotetext{
${ }^{89}$ Elisa Ruiz García, «El sueño...», p. 12.

${ }^{90}$ Sagrario López Poza, «La divisa de las granadas del rey Enrique IV de Castilla y su estela posterior», en Imago: Revista de Emblemática y Cultura Visual, 6 (2014), pp. 81-95.

${ }^{91}$ Este interés se manifestaría en la creación de la galería de reyes en el Alcázar de Segovia, en la que se trabajaba en 1462, y probablemente en la de los Reales Alcázares de Sevilla. Sobre estas, véase David Nogales Rincón, art. cit., 37-51.

${ }^{92}$ Lynette M. F. Bosch, «El taller de Juan de Carrión: los libro seculares», en Archivo Español de Arte, 264 (1993), pp. 353-371, pp. 354-361.

${ }^{93}$ Cfr. Fernando Villaseñor Sebastián, ob. cit., pp. 67-90.
} 


\subsection{El testimonio $E^{1}$ [B. Esc., h-II-22, ff. 110r-126r]}

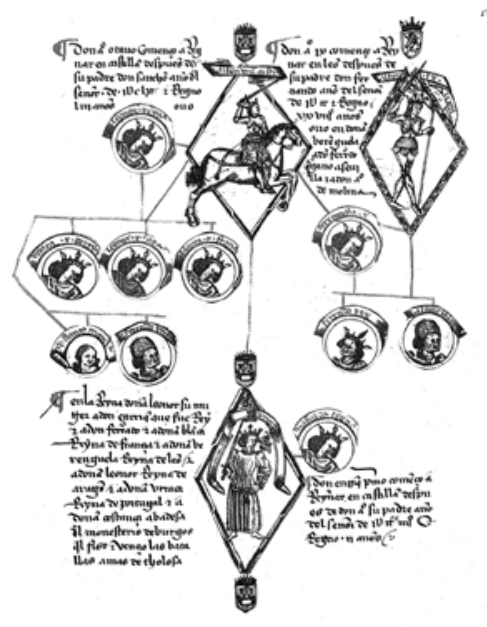

Fig 3. Alfonso VIII de Castilla, Alfonso IX de León y Enrique I de Castilla. Árbol de la genealogía de los reyes de España, B. Esc. h-II-22, f. 123r. Reproducido en Elisa Ruiz García, «El sueño de la edición múltiple: unos testimonios tempranos», en Pliegos de Bibliofilia, 8 (1999), pp. 5-24, p. 18, doc. 6.

Este testimonio se encargaría de extractar las informaciones fundamentales de la Genealogía (reyes, cronologías de reinados, vínculos familiares), con el objetivo de crear un árbol genealógico propiamente dicho (fig. 3), en el que el uso de diagramas facilitaría la comprensión de los contenidos, ayudaría a su memorización y estructuraría el texto. La fecha de realización de este ejemplar es complicada de establecer con precisión, pero es probable que nos encontremos ante un testimonio temprano, fechable, en cualquier caso, durante el reinado de Enrique $\mathrm{IV}^{94}$, por cuanto el árbol finaliza con este monarca. Otra mano posterior se habría encargado de añadir un breve texto, correspondiente al reinado de los Reyes Católicos (f. $125 \mathrm{v})$, que se acompañaría de la figuración de estos y del príncipe don Juan (f. 126r).

El ejemplar constituye un testimonio de gran interés por la presencia, en palabras de Ruiz García, de un conjunto de «improntas obtenidas mediante matrices metálicas. Luego, se ha procedido a aplicar esas pequeñas estampaciones, recortadas y pegadas, en los espacios previstos para el trazado de las correspondientes viñetas del opúsculo», dando forma a lo que Ruiz García ha denominado como una edición «quiro-metalográfica»" ${ }^{95}$. Aunque este testimonio, atendiendo a los grabados que aparecen igualmente en el testimonio $\mathrm{N}^{2}$, cabe relacionarlo con alta probabilidad con el entorno de Alonso de Cartagena ${ }^{96}$, a lo

${ }^{94}$ Elisa Ruiz García, «El sueño...», p. 10 lo data hacia 1463-1474, mientras que Luis Fernández Gallardo, «Idea...», p. 331 lo considera «la versión castellana más antigua» de la Genealogía.

${ }^{95}$ Elisa Ruiz García, «Avatares...», pp. 314-315. Igualmente Íd., «El sueño...», p. 17.

${ }^{96}$ Cfr. ibídem, pp. 21-22. Estas informaciones son, en buena medida, coincidentes con el contenido del manuscrito, que, según Elisa Ruiz y Juan Carlos Conde, mostraría los intereses historiográficos del entorno de Alonso de Cartagena. Cfr. Elisa Ruiz García, «El sueño...», p. 17; Juan C. Conde, ob. cit., p. 142, nota 51 y p. 196. Cabe recordar que pertenece a este círculo el autor de uno de los árboles genealógicos regios redactados en la Castilla de la segunda mitad del siglo xv, Diego Rodríguez de Almela y su Árbol de la genealogía de los Reyes de Portugal, estudiado en David Nogales Rincón, art. cit., 31. 
largo de la segunda mitad del siglo Xv hubo de llegar a la corte de los reyes de Castilla, pues aparece entre los libros de Isabel I de Castilla ${ }^{97}$.

En relación con el programa iconográfico ${ }^{98}$, cabe señalar que se utilizaron once tipos figurativos diferentes -enmarcados por losanges y círculos, y con un espacio en blanco, a manera de filacteria, para añadir la identificación textual de la imagen correspondiente-, repetidos a lo largo del árbol, los cuales debieron de ser añadidos de forma paralela a la redacción del texto. La tipología de varias de las figuras representadas y el diseño tanto de la corona de los escudos como de algunos de los muebles heráldicos parecen apuntar hacia tipos foráneos. Aunque no es posible determinar si las imágenes fueron realizadas ex profeso para ilustrar la Genealogía, parece posible sugerir, atendiendo a la uniformidad de los enmarques y tamaño de las imágenes, que todas ellas hubieron de ser creadas en el marco de un programa unitario. Aunque un mejor conocimiento acerca de la recepción de estas imágenes impresas en la península ibérica permitirá definir con mayor claridad sus usos, cabe señalar que su presencia en manuscritos no debió de ser un hecho inédito ni en la Península, como muestra la Carta de Juan de la $\operatorname{Cosa}^{99}$, ni, por supuesto, en el contexto europeo ${ }^{100}$.

\subsection{El testimonio $N^{4}$ [BNE, Vitr. 19/2]}

La cronología de este manuscrito ha sido fijada tradicionalmente entre 1526-1539, habiéndose relacionado con la emperatriz Isabel, mujer de Carlos V (1516-1556) ${ }^{101}$, si bien, como sugiere José Luis Gonzalo Sánchez-Molero, el códice pudo ser quizá finalizado tras su muerte ${ }^{102}$. De aceptar que estuvo dirigido a Isabel de Portugal, su confección se podría tal vez poner en relación con el importante papel político asignado a la emperatriz y al deseo de equipararla a Isabel I de Castilla ${ }^{103}$; hecho que pudo inducir a la confección de un códice que, a manera de manual, orientara a esta sobre la Historia de Castilla.

\footnotetext{
${ }^{97}$ Cfr. Elisa Ruiz García, Los libros de Isabel la Católica. Arqueología de un patrimonio escrito, Salamanca, Instituto de Historia del Libro y de la Lectura, 2004, p. 386.

${ }^{98}$ El programa iconográfico ha sido minuciosamente estudiado en Elisa Ruiz García, «El sueño...», pp. 19-21, por lo que solo llamaremos la atención sobre algunas cuestiones específicas.

${ }^{99}$ Luisa Martín-Merás, «La Carta de Juan de la Cosa: interpretación e historia», en Monte Buciero, 4 (2000), pp. 71-86, p. 76.

${ }^{100}$ David S. Areford, The Viewer and the Printed Image in Late Medieval Europe, Farnham, Burlington; Ashgate, 2010 pp. 65-103; Jonathan J.G. Alexander, ob. cit., p. 49.

${ }^{101}$ Anna Muntada, art. cit., pp. 183, 170.

${ }^{102}$ José L. Gonzalo Sánchez-Molero, Regia Bibliotheca. El libro en la Corte española de Carlos $V$, Mérida, Editora Regional de Extremadura, 2005, p. 221. Frente a esta hipótesis, Muntada sugiere la posibilidad de identificar este con la referencia a un «libro grande $[\ldots]$ ques de pargamyno y esta enl el nasçimyento de los Reyes» del Libro del inventario de la recámara de la Emperatriz, Anna Muntada, ob. cit., p. 171

${ }^{103}$ José L. Gonzalo Sánchez-Molero, ob. cit., pp. 221-222.
} 


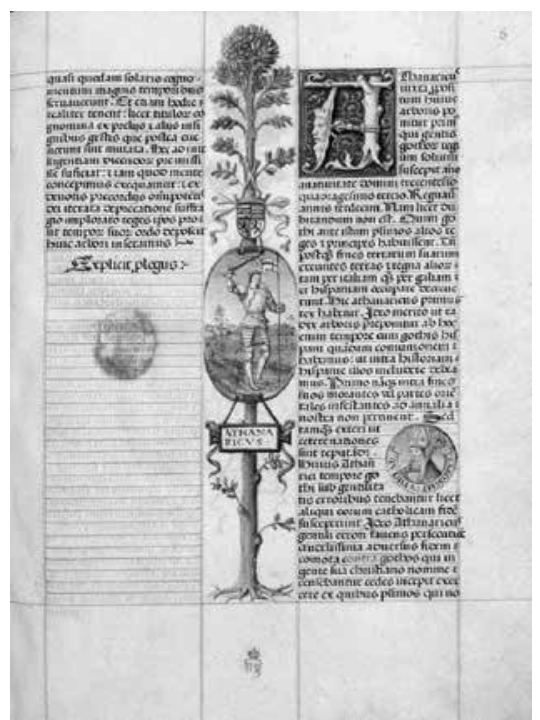

Fig. 4. Atanarico. Alonso de Cartagena, Liber genealogiae regum Hispanie, BNE, Vitr. 19/2, f. 8r. Reproducido en Anna Muntada, «Un ejemplar de la Genealogía de los Reyes de España de Alonso de Cartagena en manos de la emperatriz Isabel de Portugal», en Bulletí del Museu Nacional d'Art de Catalunya, 2 (1994), pp. 169-184, p. 172, fig. 2.

Al margen de sus aspectos artísti$\cos ^{104}$, cabe destacar, en lo que respecta a su diseño visual e iconografía, la estrecha relación, sobre la que Tormo llamó genéricamente la atención ${ }^{105}$, entre este testimonio y $\mathrm{E}^{1}$. Los modelos iconográficos, la propia relación texto-imagen y probablemente el protagonismo de la emblemática de este ejemplar parecen derivar del testimonio $\mathrm{E}^{1}$. Dicho testimonio proporcionó un conjunto de imágenes -especialmente oportunas para la representación de la realeza histórica castellana- incardinadas en la tradición iconográfica medieval, seriadas y especialmente apropiadas, por su tipología, para ser incorporadas a un árbol genealógico formulado bajo una estética renacentista, con elementos característicos como los trophea, los motivos a candelieri, las cartelas y los fondos de inspiración nórdica (fig. 4).

\section{Conclusión}

Los distintos testimonios analizados de la Genealogía muestran el papel de la imagen como elemento fundamental en los procesos de memorización e intelección del texto. Aunque futuras aproximaciones habrán de precisar algunos de los aspectos aquí señalados, parece posible apuntar al protagonismo que, a lo largo del tercer cuarto del siglo Xv, hubo de tener el entorno de Alonso de Cartagena y de Enrique IV de Castilla en la recepción de la obra. Si el primero debió de mostrar un interés ante todo intelectual por la obra de Cartagena en el marco de sus actividades historiográficas, quizá la atención del segundo se podría poner en estrecha relación con el desarrollo

${ }^{104}$ Sobre estos véase: Elías Tormo, ob. cit., pp. 241-256; Anna Muntada, art. cit., passim; María José Redondo Cantera; Vitor Serrão, «El pintor portugués Manuel Denis, al servicio de la Casa Real», en $E l$ arte foráneo en España. Presencia e influencia, Madrid, Consejo Superior de Investigaciones Científicas, 2005, pp. 61-78, p. 64.

${ }^{105}$ Elías Tormo, ob. cit., p. 287. 
de algunas estrategias de carácter propagandístico y legitimador, en un contexto marcado por el enfrentamiento del rey con parte de la nobleza del reino, que culminaría en 1465 con la proclamación como rey de Alfonso XII de Castilla (1465-1468) ${ }^{106}$. Estas estrategias, materializadas hipotéticamente en el testimonio $\mathrm{P}$, se centrarían argumentalmente en la antigüedad del linaje de los reyes castellano-leoneses, buscando -a través de un códice en el que primaba el diseño visual- realzar su prestigio y su poder soberano, conforme al pasaje de Diego Enríquez del Castillo, capellán y cronista del monarca, quien señalaba, en su Crónica de Enrique IV, que el monarca «con los prínçipes y rreyes hera, y con los más poderosos hera muy presuntuoso; preçiávase tanto de la sangre rreal suya y de sus antepasados que aquella sola dezýa ser la más exçelente que ninguna de los otros rreyes cristianos ${ }^{107}$.

Recibido: 9/04/2016

Aceptado: 26/05/2016

${ }^{106}$ Sobre estos aspectos, remitimos al trabajo de Dolores Carmen Morales Muñiz: Alfonso de Ávila, rey de Castilla, Ávila, Institución Gran Duque de Alba de la Diputación Provincial, 1988.

${ }^{107}$ Diego Enríquez del Castillo, Crónica de Enrique IV, ed. de Aureliano Sánchez Martín, Valladolid, Universidad de Valladolid, 1994, cap. I, p. 135.

*Encontrándose en prensa este trabajo, hemos podido observar, en el testimonio del Policraticus de Juan de Salisbury, perteneciente a Alonso Carrillo (1452) y procedente de la biblioteca del Marqués de la Romana, BNE, ms. 10143, f. 88v, la presencia, en el margen del folio, de una imagen femenina coronada, posible representación de la Fortuna, de escasa calidad y realizada con posterioridad a la confección del manuscrito, que guarda un paralelo cercano con algunas figuraciones del testimonio A, particularmente llamativo en lo que a la tipología de la corona se refiere. 


\title{
$\cos$
}

\section{La Genealogía de los reyes de España de Alonso de Cartagena:} LINAJE E IMAGEN REGIA EN LA CASTILla DEL CUATROCIENTOS

RESUMEN: En el presente trabajo se estudiarán los distintos testimonios manuscritos latinos y castellanos de la Genealogía de los reyes de España de Alonso de Cartagena, las posibles relaciones entre los mismos y su contexto de recepción a partir del estudio del programa iconográfico proyectado por su autor y de su materialización en los diferentes programas iconográficos conocidos (testimonios $\mathrm{A}, \mathrm{P}, \mathrm{E}^{1}, \mathrm{~N}^{4}$ ). Asimismo, se abordarán las relaciones texto-imagen, en torno al papel que esta última desempeña en el marco de las estrategias de funcionamiento de la memoria artificial dentro del ars memoriae de tradición clásica.

PALABRAS ClAVE: Genealogía. Historiografía. Iconografía. Memoria. Realeza.

\section{The Genealogía de los Reyes de España of Alonso de Cartagena: LineAge AND Royal IMAGE IN CASTILE DURING THE 15TH CENTURY}

\begin{abstract}
In the present work will be studied the different Latin and Castilian manuscript testimonies of the Genealogía de los reyes de España of Alonso de Cartagena, and the possible relationships between them and their context of reception addressed from the study of the iconographic program devised by the author and its materialization in the different known iconographic programs (testimonies A, P, E1, N4). Moreover, text/image relationships will be also analyzed, in reference to the role that the latter plays in the functioning of artificial memory strategies within the classical ars memoriae.
\end{abstract}

KeYwords: Genealogy. Historiography. Iconography. Memory. Kingship. 